\title{
Psychological Effects of Orthognathic Surgery
}

\author{
Shalini Parihar* and Sudhanshu \\ Department of Dentistry, India \\ *Corresponding Author: Shalini Parihar, Department of Dentistry, India.
}

Received: May 27, 2020

Published: June 01, 2020

(C) All rights are reserved by Shalini Parihar and Sudhanshu.

\section{Introduction}

Orthognathic surgery refers to a group of corrective bone operations that involve movement of the jawbones completely or in parts [1]. Orthognathic surgery is indicated when there are severe dentofacial deformities that cannot be managed by orthodontic treatment alone, especially in adulthood, when the natural growth forces have ceased [2]. Dentofacial deformities are described as deformities that affect primarily the jaws and dentition. The limitation can reach to one jaw or can go beyond that leading to multiple craniofacial indications which can be corrected by orthognathic surgery. The anatomical defects include psychological factors and also other factors such as biophysical ones which effect need of the treatment. In several studies aesthetic improvement is major reason for having orthognathic surgery that is why it is basic demand in various cases. Orthognathic surgery depends on patients motivation and study by Edgerton and Knorr there are 2 types of motivation - internal and external. External motivations include the need to please others, "paranoid" ideas and beliefs that one's career or social ambitions are being thwarted by physical appearance. The ones inner desire and inner beliefs play an important role for going through the surgical treatment so that the appearance would change accordingly. The inner belief and motivation is having very much importance. The one could have inner motivation by the longstanding low feelings about the appearance. Such individuals are better candidates for orthognathic surgery. The term Neuroticism is described as long-term tendency to be in negative or anxious emotional state. This neuroticism effect is seen in early postoperative phase as negative effect but not on long term outcome. Dysmorphophobia is the term described as feeling unattractive despite having almost normal appearance and this is depend on psychology of patients so they first need a psychiatrist rather than an orthognathic surgeon. Most of the orthognathic surgery patients are psychologically normal according to study by Pogrel and Scott. They also mentioned that such patients need not any psychological evaluation prior to surgery. Biophysiology phenomenon among human beings are similar in entire world but psychological effects may vary in different cultures. Surgical benefits entirely depends on evaluation of patients expectations and preoperative surgical assessment. Satisfaction arises due to surgery effect the ones selfesteem and body image. Outcome of surgery determined by results examined by the patients expectations and perspective of integration of body image [3-10].

\section{Conclusion}

The two orthognathic groups were associated with low levels of anxiety and Post Traumatic Stress Disorder symptoms in comparison with the control group of the study. Trauma exposure prior to orthognathic treatment can be considered as a risk factor for the development of dental anxiety and PTSD symptoms. The need to improve communication between patients and team is emphasized, especially during the assessment of patients' emotional state pre-operatively, in addition to discussing psychological issues and psychosocial treatment implications. It is seen that during surgical period patients suffer from stress, anxiety, Depression etc. which affect mental health of patient and patient started feeling that treatment is going only for causing trauma to them. Hence patients first motivated from the examples of other patients and tell them that procedure can result in only $50 \%$ accuracy sometime. Satisfaction from surgery arises during starting phase of the treatment but sometimes it decline gradually. The decline is usually reported by the ones who were suffering from pain, paresthesia and oral dysfunction problems caused due to surgery rather than psychological effects. The steps should be taken to minimize these effects and encouragement of patient undergoing treatment is essential so that these problems suffered by the patient considered to be minimal by himself. Psychology of the patient is important in this regard as if himself is ready to bear these minimal discomfort then he will surely have his resultant outcome (improved self-esteem related to improved facial appearance). 


\section{Bibliography}

1. Olson RE and Laskin DM. "Expectations of patients from orthognathic surgery”. Journal Oral Surgery 38.4 (1980): 283285.

2. Hutton CE. "Patients' evaluation of surgical correction of prognathism: Survey of 32 patients". Journal Oral Surgery 25.3 (1967): 225-228.

3. Crowell NT., et al. "Survey of patients' attitudes after surgical correction of prognathism: Study of 33 patients". Journal Oral Surgery 28.11 (1970): 818-822.

4. Wictorin L., et al. "Biological and psycho-social factors in patients with malformations of the jaws". Scandinavian Journal of Plastic and Reconstructive Surgery 3.2 (1969): 138-143.

5. Hillerström K., et al. "Biological and psycho-social factors in patients with malformations of the jaws". Scandinavian Journal of Plastic and Reconstructive Surgery 5.1 (1971): 134-140.

6. Laufer D., et al. "Patient motivation and response to surgical correction of prognathism". Oral Surgery 41.3 (1976): 309313.

7. Eysenck HJ. "In: Manual for the Eysenck Personality Inventory". $3^{\text {rd }}$ Editions, San Diego (1968).

8. Fitts WH. "In: Manual for the Tennessee Department of Mental Health Self-Concept Scale". $3^{\text {rd }}$ Editions, Tennessee Department of Mental Health, Nashville (1965).

9. Secord PF and Jourard SM. "The appraisal of body cathexis: Body cathexis and the self". Journal of Consulting Psychology 17.5 (1953): 343-347.

10. Kiyak HA., et al. "Predicting psychological responses to orthognathic surgery". Journal of Oral and Maxillofacial Surgery 40.3 (1982): 150-155.

\section{Assets from publication with us}

- Prompt Acknowledgement after receiving the article

- Thorough Double blinded peer review

- Rapid Publication

- Issue of Publication Certificate

- High visibility of your Published work

Website: www.actascientific.com/

Submit Article: www.actascientific.com/submission.php Email us: editor@actascientific.com

Contact us: +919182824667 